\title{
THE EXPERIMENTAL PRODUCTION OF LOSS OF HEMATOPOIETIC ELEMENTS OF THE GASTRIC SECRETION AND OF THE LIVER IN SWINE WITH ACHLORHYDRIA AND ANEMIA
}

\author{
By D. K. MILLER AND C. P. RHOADS \\ (From the Hospital of the Rockefellex Institute for Medical Research, New York City)
}

(Received for publication September 17, 1934)

The mode of origin of pernicious anemia and of conditions symptomatically allied to it, sprue and tropical macrocytic anemia, has been the subject of detailed and extensive investigation during the last decade. Although considerable advances have resulted from clinical studies in spite of limited material, one of the chief handicaps to more rapid progress has been the difficulty of reproducing similar diseases in animals. Certain isolated pathological changes including glossitis, macrocytic anemia and achlorhydria, similar to those of pernicious anemia, have been caused to occur independently, but in no reported instance have the major pathological and physiological alterations of pernicious and allied anemias been produced as a disease syndrome in a lower animal species.

The present communication deals with the results of an attempt to cause in swine a symptomcomplex which might be etiologically, symptomatically, therapeutically and pathologically similar to that characterizing the group of macrocytic anemias of man. The condition studied was brought about by the administration of a specially devised diet, and was marked by hematological, lingual and gastro-intestinal changes similar to, though not entirely identical with, those of pernicious anemia and of conditions allied to it.

To comprehend thoroughly the rationale of the experiments to be reported, a brief review is required of the conditions in human beings which it was desired to simulate.

Pernicious anemia, the anemia of sprue, and tropical macrocytic anemia, present hematological changes which are, in a general way, similar. A further likeness lies in the fact that all three may be alleviated by the administration of whole liver or of a suitably prepared extract. Distinct differences exist, however, among which are the dissimilar effects following the administration of a lysate of brewers' yeast. Whereas the symp- toms of tropical macrocytic anemia are regularly alleviated by the administration of that material, favorable results are only occasionally obtained in sprue and in pernicious anemia. If, in the latter two conditions, however, the administration of the yeast extract is supplemented by the administration of normal gastric secretion, which, by itself, is inactive, the combination is therapeutically active (Strauss and Castle (6)). The most plausible explanation of the foregoing facts is that all three symptom-complexes are due to the same fundamental cause-a lack of some substance such as that contained in the yeast cell. Such a lack may be a simple dietary insufficiency, as in the case of tropical macrocytic anemia, or it may be an insufficiency, existing even in the presence of adequate dietary intake, due to the inability of the body to utilize the substance. In pernicious anemia, and in certain cases of sprue, it would appear that an as yet unidentified gastric ferment is required for the conversion of the principle in the yeast to a hematopoietic factor.

Clinical observation suggests that in both sprue and pernicious anemia an early stage in the sequence of pathological events is an inflammatory change of the mucous membranes without anemia. This is manifested visibly by glossitis, stomatitis, proctitis or vaginitis, and symptomatically by oesophageal and gastro-intestinal pain and distress and by diarrhea. This first stage is not necessarily associated with either achlorhydria or determinable hematological disturbance. As the disease progresses, the changes affecting the mucous membranes become less acutely inflammatory and more atrophic in nature. Gastric achlorhydria, loss of hematopoietic activity of the gastric juice, and anemia, may develop in the order named. Experimental studies of sprue by Castle and Rhoads (1) established the fact that the acutely inflammatory changes in the mucous membranes are quite as susceptible to cure by the administra- 
tion of yeast extract as is the hematological syndrome of macrocytic anemia. It seems probable, therefore, that the inflammatory lesion of the mucous membrane is due to a lack in intake of, or an inability to utilize, some constituent of yeast. It is inferred, from the symptomatology, that the lesions of the mucous membrane seen in the oral cavity are simply visible examples of similar lesions throughout the gastro-intestinal tract. The conclusion is drawn that these changes so alter the gastric mucosa that it is unable to secrete a ferment capable of converting the essential principle of yeast extract into a substance required to effect hematopoiesis.

If this hypothesis is true, a method of reproducing the pathological states under discussion is apparent. Diets should be so arranged as to omit the required constituent of brewers' yeast. Unfortunately, such a procedure is impossible at present because the identification of that constituent has not been achieved. Hence, artificial diets, lacking only that substance, cannot be supplied. Another experimental approach exists, however, in the study of those pathological states in animals which may be prevented or cured by that fraction of brewers' yeast which is curative in man. The significance of such experiments would be more definite if the condition in the animal presented some symptomatic similarity to the disease of human beings under discussion. Such a condition is at hand in canine black-tongue.

The literature bearing on the subject of blacktongue in dogs has been recently reviewed by the authors (2) and need not be discussed here. It suffices to state that, as originally described, it is an acute disease, characterized by stomatitis, glossitis, salivation, diarrhea and prostration. It is nearly always fatal if untreated, or if treated late. A decrease in the number of circulating polymorphonuclear leukocytes is frequently a terminal feature (3).

As shown by Goldberger and Wheeler (4), black-tongue can be produced at will in dogs by feeding a diet composed principally of corn meal, but also containing casein, sugar, cottonseed oil, cod liver oil, and a salt mixture. It may be prevented, or, if treated in the early stages, cured, by yeast or meat, or less certainly by a variety of foodstuffs, mostly of animal origin. The factor preventing black-tongue is resistant to autoclaving. A rough parallelism was shown to exist between the distribution of the heat-labile, water-soluble, anti-neuritic vitamin $\mathrm{B}$ and the factor preventing black-tongue. The latter was thus held to be a part of the vitamin B complex, and, as such, it was tentatively identified with vitamin $B_{2}$, a term later changed by certain authors to vitamin $G$.

The nature and action of vitamin $B_{2}(G)$ is still not completely clear. As applied to any thermostable fraction of foodstuffs possessing biological activity, it clearly may include a variety of substances of different composition and action. The accepted method of both qualitative and quantitative estimation of vitamin $B_{2}(G)$ is based upon the power of that vitamin to promote growth of young rats fed diets complete except for the thermostable factor. Direct comparison of the factor preventing black-tongue and the one promoting rat-growth has unfortunately received little study, and it is still not certain whether those two factors are or are not identical.

The authors (2) reported hematological studies of dogs in which chronic recurrent black-tongue was caused. This was effected by slight changes in the diet producing black-tongue, and by treating insufficiently the acute phase of the disease. In those animals an anemia of moderate degree appeared which was frequently macrocytic in type. In its response to oral therapy it presented certain points of similarity to the anemia of sprue and pernicious anemia. The pathological changes in the mouth, tongue and bone marrow resembled those of sprue and pernicious anemia. In certain respects, however, the likeness was not complete. The anemia produced in the experimental animal was not progressive, it was not constant, it was associated with neither hyperbilirubinemia nor achlorhydria, and it was not relieved by the parenteral administration of liver extract. Furthermore, it appeared that the dog, due to a certain characteristic of the species, was not suitable for the production of a pathology identical with that of the human disease.

We have discussed somewhat the mode of production of the gastric dysfunction which precedes the hematological changes of pernicious anemia. This dysfunction has been attributed to an insufficiency in intake or utilization of some constituent 
of yeast. If this is correct, the similar changes in the mucous membrane of canine black-tongue should be followed by gastric achlorhydria and loss of the hematopoietic power of the gastric juice, since a similar fraction of yeast is prophylactic and therapeutic in that condition. Experimentally, this was not the case in the dog. Achlorhydria occurred, but only irregularly and as a late event. The hematopoietic power of the gastric juice could not be estimated because it was found that such a power is not possessed by the gastric secretion of normal dogs. Furthermore, Richter, Ivy and Meyer (5) showed that dried, defatted dog's stomach does not possess the hematopoietic effect which is present in high concentration in swine stomach. As would be expected if the antianemia effect of liver were due to a stored product dependent partly upon the activity of a gastric enzyme for its formation, Strauss and Castle (6) found canine liver to be low in anti-perniciousanemia power. This fact has been confirmed by Richter, Ivy and Meyer (5).

This being the case, it was clear that by experiments on dogs one of the major aims of the study could not be attained, i.e., an induced inability of the animal stomach to secrete antianemic factor, since in the dog no considerable amount of that factor is present under normal conditions. It is present normally in swine, however, as shown by the employment of hog's stomach as a commercial preparation for the treatment of pernicious anemia. Hence, it was decided to continue the study, substituting the swine for the dog as an experimental animal.

\section{REVIEW OF LITERATURE}

The literature on the attempted experimental production of anemia in animals may be discussed under several headings.

Gastric dysfunction is a prominent etiological factor in pernicious anemia and in sprue; furthermore, the former has been reported to follow extirpation of the stomach in human beings. Elaborate experiments involving gastric resection in animals have been reported by Maison and Ivy (7), and in their publications the literature bearing on the subject has been thoroughly reviewed and discussed. It suffices to state here that gastrectomy in rats, pigs and dogs results only in a hypochromic anemia which is curable by iron. Some other factor than the gastric is clearly required for the production of an anemia of the macrocytic type. That this other factor may have to do with the intestine was suggested by Maison and Ivy (7), and this suggestion is supported by the observations of Seyderhelm et al. (8). The latter produced a macrocytic anemia in dogs by causing a stenosis of the small intestine. That the extra-gastric factor is not wholly a lack of an intestinal secretion is suggested by unpublished experiments in this laboratory. All but a few centimeters of the ileum of dogs was resected with the resultant production of only a mild hypochromic anemia. Apparently, some disorder involving both the stomach and intestine is required to produce the desired result. This may explain the observations of Brown (9), who found that pernicious anemia was almost invariably associated with lesions of the gastro-intestinal tract, but that the lesions might be located at almost any level and might be of almost any type.

Experiments dealing with the production of nutritional anemia in animals have recently been reviewed by Davidson and Leitch (10). The microcytic anemias resulting from the feeding of diets poor in iron or copper are well known, but have little application to the problem under discussion. Both iron and copper deficiencies are associated with a greater reduction of hemoglobin than of erythrocytes, and are specifically relieved by the administration of the lacking element. The anemias found in man associated with the conditions under discussion are not so characterized. A hypochromic or microcytic anemia occurs in the experimental blood dyscrasias which depend for their production upon depletion of the available hemoglobin stores by bleeding. Experiments of that type have been exhaustively studied by Whipple and RobscheitRobbins (11). The anemia produced was not entirely due to a lack of iron, although the administration of iron accelerated the production of hemoglobin. Some other factor was presumably involved, since the dogs had been fed a somewhat restricted diet, and certain foodstuffs added to the diet were effective, exclusive of their iron content, in causing increase of hemoglobin in the blood.

The work of McGowan and Sinclair (12) has a definite bearing upon the studies here presented. $\mathrm{He}$ observed that young pigs kept on a ration of corn, fish meal and draff became ill with anemia, damage to the liver, jaundice and changes in the bone marrow. The anemia was, in many instances, of the macrocytic type, and following the administration of raw liver reticulocyte rises occurred, with subsequent cure. They state that during the height of the anemia the femoral marrow was red and cellular. It became fatty once more as recovery proceeded. Moreover, gastric juice obtained at postmortem, in one instance was devoid of free hydrochloric acid. Unfortunately, no detailed studies of the composition of the diet, of the histology of the bone marrow, of the possible changes in gastric secretion, or of the comparative effects of various therapeutic methods, were reported.

The extensive literature dealing with the conception that canine black-tongue is to be regarded as experimental pellagra, and with the content of the factor preventing black-tongue in various foodstuffs, has been referred to and needs no review here. The effect on the gastric secretion of dogs from feeding diets deficient in vitamin $B_{1}$ 
has been described by Cowgill and Gilman (13). Changes in the central nervous systems of dogs fed diets deficient in vitamin $B_{2}(G)$ rather than in anti-neuritic vitamin have been published by Zimmerman and Burack (14). Since the diet used in the experiments reported in this communication produced canine black-tongue, but was found to contain both of these essential food substances when tested on the rat, it is difficult to evaluate the pertinence of those previous studies in which there was an almost complete lack of the vitamin B fractions.

\section{METHODS}

Swine weighing from 11 to $13 \mathrm{kgm}$., and of both sexes, were used. The animals were kept in individual cages during the winter, but were in a single pen in the open air during the summer months; with this exception, the conditions were uniform. Shavings were employed as bedding. No attempt was made to prevent coprophagy. The animals were fed daily and were allowed to eat as much as they desired. The experimental diet used was a modification of the Goldberger and Wheeler (4) diet No. 123 which produces black-tongue. It consisted of the materials shown in Table A.

TABLE A

Composition of experimental diet

\begin{tabular}{|c|c|c|c|c|}
\hline \multirow{2}{*}{ Articles of diet } & \multirow{2}{*}{ Quan- } & \multicolumn{3}{|c|}{ Nutrients } \\
\hline & & $\begin{array}{l}\text { Pro- } \\
\text { tein }\end{array}$ & Fat & $\begin{array}{l}\text { Carbo- } \\
\text { hydrate }\end{array}$ \\
\hline 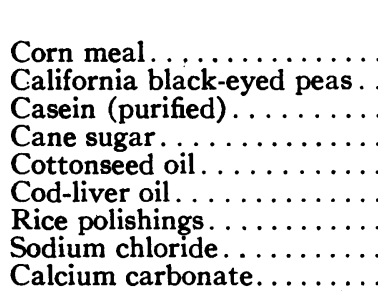 & \begin{tabular}{|c} 
grams \\
400 \\
50 \\
60 \\
32 \\
15 \\
30 \\
40 \\
3 \\
10
\end{tabular} & $\begin{array}{c}\text { grams } \\
33.6 \\
10.7 \\
52.0\end{array}$ & $\begin{array}{c}\text { grams } \\
18.8 \\
0.7 \\
\\
30.0 \\
15.0\end{array}$ & $\begin{array}{r}\text { grams } \\
296.0 \\
30.4 \\
32.0\end{array}$ \\
\hline $\begin{array}{l}\text { Total nutrients } \ldots \ldots \ldots \\
\text { Nutrients per } 1000 \text { calories }\end{array}$ & & $\begin{array}{l}96.3 \\
40.1\end{array}$ & $\begin{array}{l}64.5 \\
26.9\end{array}$ & $\begin{array}{l}358.4 \\
149.3\end{array}$ \\
\hline
\end{tabular}

In order to ascertain the effect of a deficiency of vitamins, other than of the water-soluble vitamin B complex, control experiments were performed. Swine similar to those used in the major experiment were kept under similar conditions and were fed a diet which was vitamin deficient, but was otherwise adequate. By adding suitable supplementary materials this diet could be made deficient in any single vitamin or combination of vitamins which it was desired to study. The basal diet used was the one recommended by Cowgill and Gilman (13) and consisted of the ingredients shown in Table B.

Erythrocyte counts, hemoglobin determinations, white cell counts and estimations of the mean corpuscular volume were made weekly as a routine and more frequently if indicated. All determinations were made on blood
TABLE B

\section{Composition of basal diet}

Casein (purified) $\ldots \ldots \ldots \ldots \ldots \ldots \ldots \ldots, 35.4$ grams

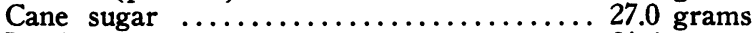

Lard ......................... 21.6 grams

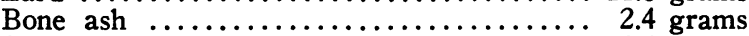

Salt mixture (Mendel and Underhill) ...... 2.4 grams

Water ............................ 12.2 grams

from the femoral vein. The erythrocytes were counted in the usual manner, using pipettes certified for accuracy by the U. S. Bureau of Standards. The hemoglobin determinations were made by the Sahli acid hematin method, using calibrated tubes and standards which were frequently checked by the Van Slyke (15) method of determining $\mathrm{O}_{2}$ capacity. The mean corpuscular volume was calculated by the hematocrit method of Wintrobe (16). Reticulocytes were stained by allowing the wet blood smear to come in contact with dry brilliant cresyl blue stain. They were later counterstained by Wright's method.

Studies of the gastric secretion were made on all the animals at two-week intervals. Only two samples were examined, one obtained from the fasting stomach and a second withdrawn from 20 to 30 minutes after the intramuscular injection of histamine. These specimens were titrated in the usual way with 0.1 normal $\mathrm{NaOH}$, using Töpfer's reagent and phenolphthalein as indicators. Control studies of the histology of the bone marrow of the experimental animals were made on tissue removed at operation from the femur. ${ }^{1}$

All of the swine were autopsied, at which time specimens of various tissues including the bone marrow were fixed in Zenker's fluid containing 5 per cent acetic acid as well as in a 10 per cent solution of formaldehyde in Zenker's fluid. The tissues fixed in the Zenker's fluid with acetic acid were stained with eosin and methylene blue. Material fixed by other fluids was stained by the Giemsa method as modified by Wolbach (17).

Gastric juice in amounts sufficient to allow it to be tested for its content of anti-pernicious-anemia substance was obtained from individual swine which had been allowed no food for twenty-four hours. A stomach tube was inserted and the fasting gastric content was removed and discarded. One cubic centimeter of a 1:1000 dilution of histamine was then injected intramuscularly and all the fluid secreted in response to that stimulus was collected. Great care was exercised to keep the gastric juice cold and strongly acid until it was used.

In preparing the mixtures of gastric juice and yeast extract, the juice was first filtered through fine gauze. Twelve grams of yeast extract (Vegex ${ }^{2}$ ) were then suspended in each $150 \mathrm{cc}$. of the fluid. The mixture was incubated at $37.5^{\circ}$ for one hour, its $\mathrm{pH}$ adjusted to 6 with concentrated $\mathrm{NaOH}$ and the material fed immediately to patients with pernicious anemia.

1 All surgical procedures were carried out under full ether anesthesia.

2 Supplied through the courtesy of Vegex, Inc., New York City. 
The livers of achlorhydric, anemic swine, as well as of normal controls, were extracted in order to test their anti-pernicious-anemia effect. The method of extraction was that described by Cohn, McMeekin and Minot (18). The fresh liver was ground into water and the resulting suspension was brought to a concentration of 70 per cent alcohol. The filtrate was then concentrated in vacuo and brought to a concentration of 95 per cent alcohol by the addition of a suitable amount of absolute alcohol. The resultant precipitate was dissolved in water, neutralized, filtered and sterilized by boiling to prepare it for injection.

The content of vitamin B in the Goldberger diet used in these experiments was determined by testing its power to promote growth in young rats. A standard procedure was employed. Animals weighing from 40 to 50 grams were fed immediately after weaning a basal diet deficient in vitamin B. They were fed only this diet for two weeks in order to ensure the complete depletion of the body store of vitamin $B_{1}$ and $B_{2}(G)$. After that time they were fed only the diet which produces black-tongue. The animals were weighed weekly and the rate of gain in weight was compared with that of rats fed a normal diet at the same season of the year. These latter data were obtained from the report of Levene (19).

\section{RESULTS}

A certain number of swine died suddenly, either before or shortly after blood changes had occurred. Some of these deaths were due to acute infections, while others could not be explained at postmortem examination. Such animals are not included in the experimental results.

In all the surviving swine a well defined symptom-complex appeared which presented certain similarities to canine black-tongue, but which was in no instance absolutely identical with that disease. The most striking manifestations were stomatitis, achlorhydria and anemia. Diarrhea, loss of appetite and weakness also occurred with fair regularity. On the basis of the type of the anemia, two distinct types of reaction were observed. In one, there was an increase in the average red cell diameter and in the hemoglobin content of each individual erythrocyte; and in the other, the reverse was true, namely, the average red blood cell was smaller and its hemoglobin content was less than normal. Accordingly, one group was designated as that with macrocytic anemia, and the other as the microcytic-anemia group.

The control animals on the basal diet failed to develop either the symptoms or the hematological changes which were so constant in the swine fed the diet producing black-tongue. Furthermore, the pathological changes of the bone marrow were wholly dissimilar.

\section{SYM PTOMATOLOGY}

A tabulation of the symptoms as they occurred in the swine of both the macrocytic- and microcytic-anemia groups is presented in Table $I$. With the exception of diarrhea, the disease manifestations other than hematological occurred more frequently in the group of animals which developed the macrocytic type of anemia. There was a striking tendency to remission and exacerbation of symptoms.

TABLE I

The incidence and time of appearance of symptoms in the three experimental groups of swine

\begin{tabular}{|c|c|c|c|c|c|c|c|c|c|c|c|c|c|c|c|c|c|}
\hline \multicolumn{7}{|c|}{ Group I macrocytic anemia } & \multicolumn{7}{|c|}{ Group II microcytic anemia } & \multicolumn{4}{|c|}{ Control swine } \\
\hline 总 & 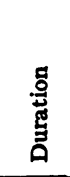 & 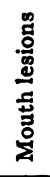 & 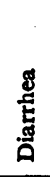 & 离 & 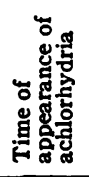 & 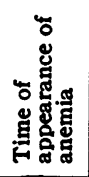 & 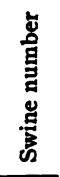 & 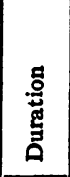 & 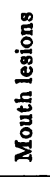 & 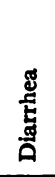 & 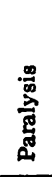 & 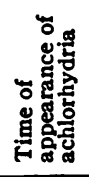 & 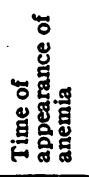 & 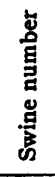 & 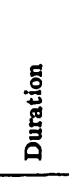 & 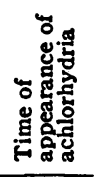 & 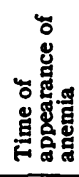 \\
\hline $\begin{array}{l}1 \\
2 \\
3 \\
4 \\
5 \\
6 \\
7 \\
8 \\
9\end{array}$ & $\begin{array}{r}\text { days } \\
74 \\
83 \\
111 \\
93 \\
132 \\
127 \\
47 \\
82 \\
121\end{array}$ & $\begin{array}{l}+ \\
0 \\
+ \\
+ \\
0 \\
0 \\
+ \\
0 \\
+\end{array}$ & $\begin{array}{l}+ \\
+ \\
+ \\
+ \\
+ \\
+ \\
+ \\
+ \\
+\end{array}$ & $\begin{array}{l}0 \\
0 \\
+ \\
+ \\
0 \\
+ \\
0 \\
0 \\
0\end{array}$ & $\begin{array}{c}\text { weeks } \\
7 \\
7 \\
11 \\
4 \\
16 \\
7 \\
6\end{array}$ & $\begin{array}{c}\text { weeks } \\
8 \\
8 \\
7 \\
6 \\
11 \\
4 \\
6 \\
4 \\
6\end{array}$ & $\begin{array}{l}10 \\
11 \\
12 \\
13 \\
14 \\
15\end{array}$ & $\begin{array}{r}\text { days } \\
51 \\
85 \\
42 \\
74 \\
65 \\
120\end{array}$ & $\begin{array}{l}\mathbf{0} \\
\mathbf{0} \\
\mathbf{0} \\
\mathbf{0} \\
+ \\
\mathbf{0}\end{array}$ & $\begin{array}{l}+ \\
+ \\
+ \\
+ \\
+ \\
+\end{array}$ & $\begin{array}{l}0 \\
0 \\
0 \\
0 \\
0 \\
+\end{array}$ & $\begin{array}{c}\text { weeks } \\
5 \\
6 \\
4 \\
6\end{array}$ & $\begin{array}{c}\text { weeks } \\
5 \\
7 \\
5 \\
4 \\
7 \\
10\end{array}$ & $\begin{array}{l}16 \\
17 \\
18 \\
19\end{array}$ & $\begin{array}{r}\text { days } \\
145 \\
100 \\
80 \\
91\end{array}$ & $\begin{array}{c}\text { weeks } \\
2 \\
3 \\
3 \\
3\end{array}$ & $\begin{array}{c}\text { weeks } \\
0 \\
0 \\
0 \\
0\end{array}$ \\
\hline Average & 98 & & & & & & & 73 & & & & & & & 104 & & \\
\hline
\end{tabular}


Oral lesions. Of the nine animals in the first, or macrocytic-anemia group, five had lesions of the lingual, buccal or pharyngeal mucous membrane. Only one animal of the six included in the second, or microcytic-anemia group, showed similar changes. The most common lesion was a circumscribed ulceration, most commonly of the lower lip or tongue, showing a red indurated border and base, and a yellow necrotic center. There was little or no localized injection about these ulcers. In the early stages the lesions were usually very small, measuring $0.2 \mathrm{~mm}$. to $0.5 \mathrm{~mm}$. in diameter. As they progressed, they coalesced to form large necrotic areas which were occasionally 1 to $2 \mathrm{~cm}$. in diameter. At that stage the ulcers were surrounded by faintly injected tissue, the margins were elevated, and the centers sharply depressed. The lesions healed slowly and often left residual scars. The time of appearance of ulceration varied considerably; in several of the animals it appeared in the fifth or sixth week after the experimental feeding was begun, while in others it occurred much later. There seemed to be a definite relation between the appearance of these lesions and the development of other symptoms, and in certain instances recurrent ulceration was a feature.

Glossitis was seen in only two animals, both of which were in the first group. The earliest manifestation was redness of the tongue along the borders and over the tip. In a few days atrophy of the papillae in those regions developed, leaving a smooth glossy surface. After a brief interval the redness faded, and the papillae regenerated. The changes were very similar to those described in chronic canine black-tongue.

Gastro-intestinal disturbances. The animals ate well until the onset of severe mouth lesions, when the food was taken reluctantly and at times refused. The majority of the animals did not lose weight until late in the disease. Diarrhea occurred in all of the animals of both groups. The stools were voluminous, soft and yellow in color. The animals, although not full-grown, failed to gain weight after the first few weeks following the institution of the diet.

Disturbance of motor function. Three of the animals which developed macrocytic anemia, and one animal showing microcytic anemia, developed striking motor weakness of the limbs during the course of the disease. The earliest manifestation was unsteadiness of the gait, which progressed until there was an apparently complete loss of motor function of the extremities. The forelegs were the last to be involved. Treatment with intramuscularly injected liver extract was effective in relieving the weakness, whereas no effect was observed following oral treatment with large amounts of a potent vitamin $B_{1}$ concentrate. $^{3}$ Hence, it appears that this symptom was not due to a lack of the anti-neuritic vitamin.

\section{Achlorhydria}

Control gastric analyses done at the beginning of the experimental feeding demonstrated the presence of free hydrochloric acid in the gastric juice of all the animals, either in the fasting contents or in the specimen obtained after the injection of histamine. In Table I are presented for all the animals the time of disappearance of free hydrochloric acid from the gastric juice after the injection of histamine. Seven of the animals of the first group developed a complete achlorhydria during the experimental feeding. In every instance except one the achlorhydria was persistent. The time at which it appeared was variable. Four of the animals of the second, or microcytic-anemia group, developed a similar achlorhydria, a change which preceded the appearance of anemia in every instance.

\section{Anemia}

Anemia occurred in all of the swine which survived more than two months. The classification of the anemia into two groups, according to the size and hemoglobin content of the erythrocytes, has been discussed. Nine of the fifteen animals presented developed a macrocytic anemia, and six developed the microcytic type.

\section{GROUP I. MACROCYTIC ANEMIA}

The maximum variation in blood values observed in the nine animals of this group, together with their original blood levels, are presented in Table II. In each instance the mean corpuscular volume and the color index were higher at the low point of the anemia than at the commence-

${ }^{3}$ Rice polishings concentrate furnished through the courtesy of the Burroughs Wellcome Company, Tuckahoe, New York. 
TABLE II

The maximum variations in blood levels in the group of swine with macrocytic anemia. Group I. Macrocytic anemia

\begin{tabular}{|c|c|c|c|c|c|c|c|c|c|c|}
\hline \multirow{2}{*}{$\begin{array}{c}\text { Swine } \\
\text { number }\end{array}$} & \multicolumn{5}{|c|}{ Blood studies before experimental diet } & \multicolumn{5}{|c|}{ Blood studies at low point of anemia } \\
\hline & R.B.C. & Hgb.† & w.B.C. & MCV* & $\mathrm{CI} *$ & R.B.C. & Hgb.† & W.B.C. & MCV & CI \\
\hline Average & 7.74 & 82 & & 48.2 & .534 & 3.66 & 46.3 & & 59.5 & .653 \\
\hline
\end{tabular}

* MCV = mean corpuscular volume.

$\mathrm{CI}=$ color index.

$\dagger \mathrm{IOO}$ per cent $\mathrm{Hgb} .=20.6$ volumes per cent $\mathrm{O}_{2}$ capacity.

ment of the experimental feeding, changes in keeping with the fact that the red blood cell count showed a greater proportionate decrease than did the hemoglobin level.

At the outset the average erythrocyte count of all the animals of this group was $7,740,000$, and the average hemoglobin level was 82 per cent. At the same time, the average mean corpuscular volume was 48.2 cubic microns, and the average color index was .534. At the low point of the anemia, the average erythrocyte count of all the animals was $3,660,000$, or a decrease of 53 per cent. The average hemoglobin level was 46.3 per cent, or a decrease of 43.5 per cent. At the same time, there occurred an increase in the average mean corpuscular volume from 48.2 to 59.5 cubic microns, or an increase of 23.5 per cent. The average color index increased from .534 to .653 , or an increase of 22.4 per cent. The disproportion between the number of erythrocytes and hemoglobin levels was reflected in the increase in the size of the average red blood cell and in the increase in its hemoglobin content.

\section{PROTOCOLS OF TYPICAL EXPERIMENTS}

Swine number 2, Figure 1

1933

June 5 Weight $13.3 \mathrm{kgm}$. Feeding of experimental diet begun.

June 12 R.B.C. $\mathbf{7 . 7 3}$ Hgb. 89\% MCV 45.0 CI $\mathbf{. 5 7 5}$ W.B.C. 24,800
Free Total

June 20 Gastric analysis: Vol. $\mathrm{HCl}$ acid. Fasting $\quad 30$ cc. $\quad 10.0 \quad 37.5$ $30^{\prime}$ p Histamine $30 \mathrm{cc} . \quad 36.5 \quad 56.3$

June 27 Weight $13.9 \mathrm{kgm}$. No symptoms.

July 5 Diarrhea has been present for four days. R.B.C. $5.31 \mathrm{Hgb}$. $52 \%$ MCV 48.0 CI .490

July 13 Gastric analysis: Vol. Free Total $\begin{array}{llll}\text { Fasting } & 15 \mathrm{cc} . & 0 & 14.5\end{array}$ $30^{\prime}$ p Histamine $19 \mathrm{cc} .0027 .5$

Ten cc. of a rice polishings concentrate by mouth has been administered daily for two days. The diarrhea has ceased.

Aug. 10 Iron ammonium citrate $1 \mathrm{gram}$ daily has been added to the diet.

Aug. 15 The animal has been symptomatically well and now has a severe anemia.

R.B.C. 3.86 Hgb. $34 \%$ MCV 68.0 CI .700 Weight $12.9 \mathrm{kgm}$.

Aug. 29 The anemia persists but the animal appears to be well otherwise.

Sept. 10 Weight $13.9 \mathrm{kgm}$. No evidence of disease except for anemia.

Sept. 16 Diet refused. Diarrhea recurred. A concentrate of rice polishings was administered in $10 \mathrm{cc}$. amounts daily by mouth.

R.B.C. 3.50 Hgb. $50 \%$ MCV 65.5 CI .715

Free Total

Gastric analysis: Vol. $\mathrm{HCl}$ acid.

$\begin{array}{llll}\text { Fasting } & 21 \text { cc. } & 16.6 & 22.2\end{array}$

$30^{\prime}$ p Histamine $\quad 30 \mathrm{cc}$. $59.5 \quad 73.6$

Free $\mathrm{HCl}$ is now present in the gastric juice and some improvement in blood values has occurred.

R.B.C. 4.64 Hgb. $51 \%$ MCV 65.5 CI .555 
Sept. 27 The animal is eating poorly and has diarrhea. R.B.C. 4.82 Hgb. $60 \%$ MCV 55.0 CI .625

Oct. 3 There are several small circumscribed ulcers of the tongue, lower lip, and pharynx. The appetite is poor and the animal appears to be ill.

R.B.C. 4.01 Hgb. $60 \%$ W.B.C. 1,600 MCV 56.0 CI .750

Oct. 4 Found dead. Autopsy: There were deep ulcerated lesions of lips, tongue, and pharynx. The marrow was deep red and appeared to be hyperplastic.

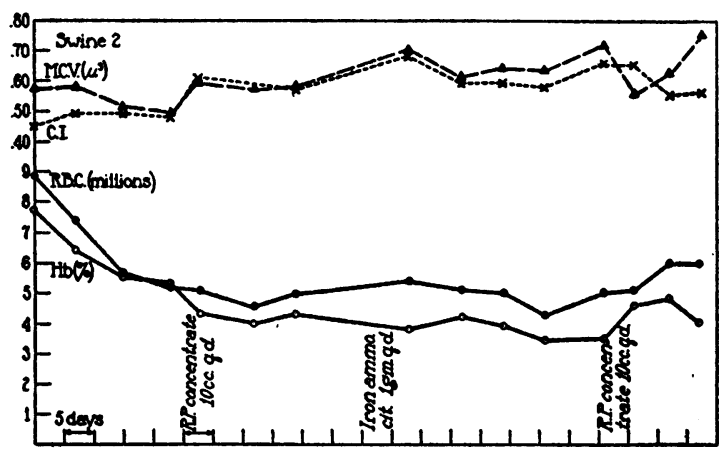

Fig. 1. Graph Showing the Changes in Blood LeVELS OF SWINE 2.

In this animal (Figure 1) recurrent mouth lesions, diarrhea, anemia and achlorhydria were present for a period of 121 days. The anemia was persistent and was accompanied by an increase in the size of the red blood cell and its hemoglobin content. No detectable effect followed the administration of iron by mouth. A rice polishings concentrate which contained a relatively large amount of vitamin $B_{1}$ and very little vitamin $B_{2}(G)$ was given during the period of achlorhydria, and no immediate improvement in the blood values was observed. How- ever, later in the experimental period free $\mathrm{HCl}$ reappeared in the gastric juice, the same concentrate of rice polishings was given and a blood remission ensued. The significance of this observation is not clear.

Swine number 3 (Figure 2)

1934

March 1 Feeding of experimental diet begun. R.B.C. 8.13 Hgb. $80 \%$ MCV 46.0 CI .495

March 7 Weight $11.8 \mathrm{kgm}$.

Free Total Vol. acid acid.

Fasting 20 cc. $28 \quad 36$

March 24 The animal has been well and has gained weight.

Weight $13.0 \mathrm{kgm}$.

April 4 R.B.C. 5.15 Hgb. 52\% MCV 47.0 CI .510 No evidence of disease is present.

April 15 The diet is taken poorly. There is smoothness, atrophy, and moderate redness of the tongue. Several small circumscribed punchedout ulcers are present on the buccal mucosa. The legs are weak.

April 21 R.B.C. 3.77 Hgb. $36 \%$ MCV 45.0 CI .516 Diarrhea has been present for 4 or 5 days. The appetite is poor and the mouth lesions persist. In spite of marked weakness all the limbs can be moved. The daily intramuscular administration of liver extract in 5 cc. amounts was begun today. Reticulocyte count 0.6 per cent.

April 26 There are a very few deep circumscribed necrotic lesions of tongue and labial mucosa. Diarrhea has ceased.

R.B.C. 3.55 Hgb. $41 \%$ MCV 63.0 CI .585

Reticulocyte count 7.2 per cent.

April 28 Apparently complete motor weakness of the limbs is present. Mouth rapidly improving. No diarrhea. Eating well.

Reticulocyte count 11.2 per cent.

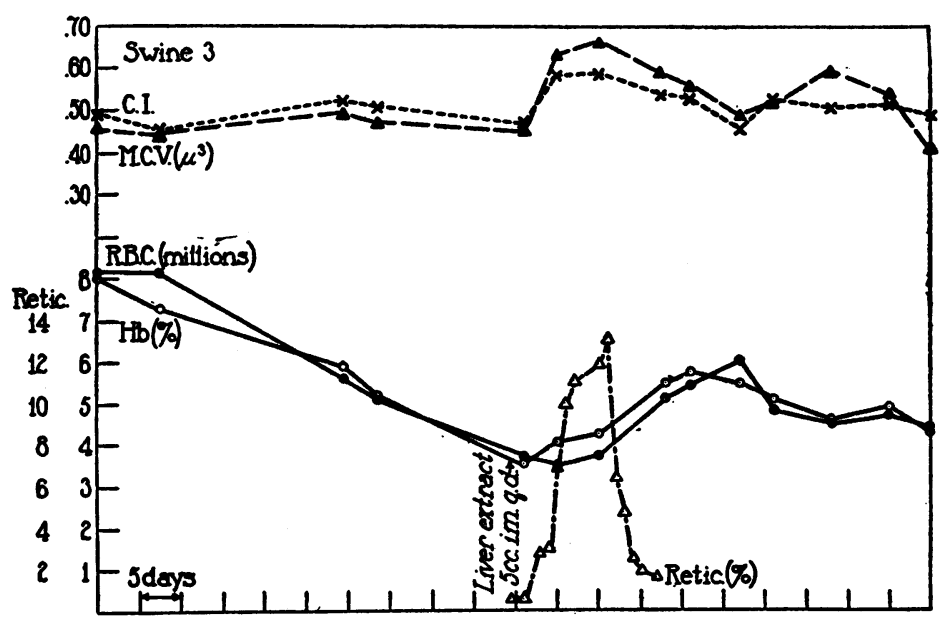

Fig. 2. Graph Showing Changes in Blood Levels of Swine 3. 
April 30 Now regaining the function of hind legs. Mouth nearly healed.

May 1 R.B.C. 3.78 Hgb. $43 \%$ MCV 66.0 CI .590 Reticulocytes 12 per cent.

May 4 Animal in good condition. Eating well and is up and about. Mouth healed. Daily injections of liver extract discontinued.

(aree Total

May 5 Gastric analysis: Vol. $\mathrm{HCl}$ acid. $\begin{array}{llll}\text { Fasting } & 11 \mathrm{cc} . & 0 & 4.7\end{array}$ $30^{\prime}$ p Histamine $\quad 30 \mathrm{cc} . \quad 0 \quad 16.9$

May 12 R.B.C. 5.45 Hgb. $58 \%$ MCV 56.0 CI .536 The animal is now in very good condition.

May 19 Refused food today. Has frequent voluminous yellow stools.

R.B.C. 6.04 Hgb. 55\% MCV 49.0 CI .460

May 24 Liver extract in ten gram amounts has been given daily by mouth for four days. The animal is now symptom-free. There is no diarrhea and the diet is taken well.

This animal (Figure 2) developed recurrent mouth lesions, a macrocytic anemia and achlorhydria. It survived for 111 days. The anemia was relieved by the daily intramuscular injection of 2.5 cc. of liver extract (Lilly number 343). A reticulocyte rise of 13.2 per cent occurred on the seventh day after the beginning of therapy, and was followed by improvement of the blood levels. The red blood cell count rose from 3,550,000 with a hemoglobin of 41 per cent to a count of $6,040,000$ and a hemoglobin of 55 per cent. There was a marked degree of weakness of the extremities which disappeared after the intramuscular injection of liver extract.

GROUP II. MICROCYTIC ANEMIA

The maximum alterations of the blood levels observed in the six animals of this group, together with the original levels, are presented in Table III. In five of the swine the mean corpuscular volume of the red blood cells was lower during the anemia than were the original values. The sixth animal, Number 15, is included in this group because the color index was not increased, although the mean corpuscular volume did not fall below the normal level. While none of these animals showed an anemia which was markedly microcytic in character, yet the contrast to the type of cell seen in the macrocytic group was striking.

The average original red blood cell count of all the animals of this group was $6,790,000$, and the average hemoglobin level was 76.9 per cent. The average mean corpuscular volume was 60.6 cubic microns, while the average color index was .570 . At the low point of the anemia the average erythrocyte count was $3,990,000$, a decrease of 41 per cent. At the same time, the average hemoglobin level had fallen to 44.6 per cent, or a decrease of 42.5 per cent. The average mean corpuscular volume fell to 48.5 cubic microns, or a decrease of 4.5 per cent, while the color index decreased to 0.556 , or a decrease of 2.25 per cent. It is apparent that the average decrease of the numbers of red blood cells was less than the average decrease of the hemoglobin values. Accompanying this anemia, the average red blood cell became smaller and its hemoglobin content was diminished in comparison with the original values.

\section{PROTOCOLS}

\section{Swine number 13 (Figure 3)}

1933

Aug. 7 Experimental diet commenced. Weight 9.3 $\mathrm{kgm}$. This animal received the modified Goldberger diet plus reduced iron, one gram daily, throughout the course of the study.

TABLE III

The average maximum variations in blood values of the experimental swine with microcytic anemia Group II. Microcytic anemia

\begin{tabular}{|c|c|c|c|c|c|c|c|c|c|c|}
\hline \multirow{2}{*}{$\begin{array}{c}\text { Swine } \\
\text { number }\end{array}$} & \multicolumn{5}{|c|}{ Blood studies before experimental diet } & \multicolumn{5}{|c|}{ Blood studies at low point of anemia } \\
\hline & R.B.C. & $\mathrm{Hgb}$. & w.B.c. & MCV & CI & R.B.C. & Hgb. & W.B.C. & $\mathrm{MCV}$ & CI \\
\hline $\begin{array}{l}10 \\
11 \\
12 \\
13 \\
14 \\
15\end{array}$ & $\begin{array}{c}\text { millions } \\
7.09 \\
6.11 \\
7.41 \\
6.00 \\
6.69 \\
7.49\end{array}$ & $\begin{array}{c}\text { per cent } \\
84 \\
67 \\
83 \\
72 \\
73 \\
82\end{array}$ & $\begin{array}{l}23,500 \\
19,300 \\
19,000 \\
15,900 \\
20,000 \\
24,700\end{array}$ & $\begin{array}{c}\text { per cent } t \\
53.5 \\
52.0 \\
48.0 \\
56.0 \\
50.5 \\
44.0\end{array}$ & $\begin{array}{l}.600 \\
.550 \\
.560 \\
.600 \\
.560 \\
.550\end{array}$ & \begin{tabular}{|c|} 
millions \\
3.87 \\
4.58 \\
3.67 \\
2.89 \\
4.22 \\
4.74
\end{tabular} & $\begin{array}{c}\text { per cent } \\
39 \\
57 \\
40 \\
31 \\
49 \\
52\end{array}$ & $\begin{array}{r}6,500 \\
7,400 \\
36,000 \\
3,950 \\
8,250 \\
12,000\end{array}$ & $\begin{array}{c}\text { per cent } \\
54.0 \\
53.5 \\
46.5 \\
42.5 \\
45.0 \\
49.5\end{array}$ & $\begin{array}{l}.515 \\
.580 \\
.555 \\
.555 \\
.585 \\
.550\end{array}$ \\
\hline Average & 6.79 & 76.9 & & 50.6 & .570 & 3.99 & 44.6 & & 48.5 & .556 \\
\hline $\begin{array}{l}\text { Per cent of } \\
\text { change }\end{array}$ & & & & & & -41.0 & -42.5 & & -4.15 & -2.25 \\
\hline
\end{tabular}


Aug. 12 Gastric analysis: Vol. Free Total $\begin{array}{llll}\text { Fasting } & 30 \mathrm{cc} . & 2.0 & 4.0\end{array}$ $30^{\prime}$ p Histamine $\quad 30$ cc. $\quad 34.2 \quad 12.2$ R.B.C. 6.44 Hgb. $96 \%$ MCV 58.5 CI .750

Aug. 25 The animal has been well and has had no symptoms.

Sept. 13 Gastric analysis: Vol. Free $\begin{aligned} & \text { Total } \\ & \text { acid. }\end{aligned}$ $\begin{array}{llll}\text { Fasting } & 5 \mathrm{cc} . & 0 & 9.6\end{array}$

$30^{\prime}$ p Histamine $17 \mathrm{cc} . \quad 0 \quad 14.4$

The animal has eaten well and is symptomfree.

Sept. 21 R.B.C. 4.46 Hgb. $48 \%$ MCV 50.0 CI .540 An anemia is now present, together with an achlorhydria. Diarrhea has occurred irregularly during the past week.

Oct. 9 R.B.C. 3.87 Hgb. $38 \%$ MCV 46.5 CI .495 The animal appears well. There is no diarrhea, but there has been some loss of weight. $\begin{array}{llll}\text { Fasting } & 9 \mathrm{cc} . & 0 & 5.2\end{array}$ $30^{\prime}$ p Histamine $15 \mathrm{cc} . \quad 0 \quad 8.0$

Oct. 17 R.B.C. 3.23 Hgb. $33 \%$ MCV 41.5 CI .515 Appears weak, has diarrhea, but is eating. The skin and mucous membranes appear yellow and the animal has a microcytic anemia.

Oct. 19 R.B.C. 2.89 Hgb. $31 \%$ MCV 42.5 CI .555 Profuse diarrhea, refused food today and appeared very weak. Sudden death occurred. Autopsy: There was an effusion of yellow bile-stained fluid in all the serous cavities. The liver presented an irregular golden brown coloration. The femoral, rib and

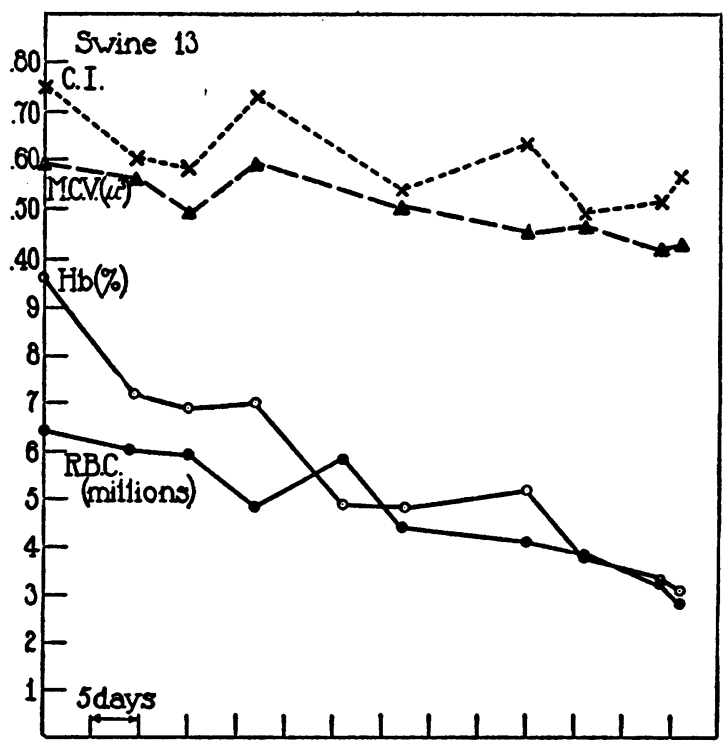

Fig. 3. A Graph of the Changes in Blood LEVELS OF SWINE 13. sternal marrows were very red and solid in consistency.

This animal is presented because the blood studies are typical of those seen in the animals of this group. It had a severe microcytic anemia although iron was administered daily during the entire period of the experimental feeding. No mouth lesions were seen. Achlorhydria developed early in the course of the disease and was persistent.

\section{Swine number 15 (Figure 4)}

1933

Aug. 7 Feeding of experimental diet begun. The diet was supplemented by one gram daily of reduced iron.

Aug. 14 Weight $12.9 \mathrm{kgm}$. R.B.C. 7.49 Hgb. 82\% MCV 44.0 CI .550

Free Total

Aug. 22 Gastric analysis: $\mathrm{Vol}$. $\mathrm{HCl}$ acid.

$\begin{array}{llrr}\text { Fasting } & 12 \mathrm{cc} . & 6.0 & 9.0\end{array}$

$30^{\prime}$ p Histamine 18 cc. $\quad 17.0 \quad 34.0$

Aug. 30 R.B.C. 7.09 Hgb. $81 \%$ MCV 46.5 CI .580 The appetite is good. There have been no symptoms.

Free Total

Vol. $\mathrm{HCl}$ acid. $\begin{array}{llrr}\text { Fasting } & 15 \mathrm{cc} . & 5.6 & 18.5\end{array}$ $30^{\prime}$ p Histamine $\quad 30 \mathrm{cc}$. $23.2 \quad 35.5$

R.B.C. 6.80 Hgb. $71 \%$ MCV 44.5 CI .520

Sept. 28 Gastric analysis: Free Total

$\begin{array}{llcc}\text { Fasting } & 11 \mathrm{cc} . & 0 & 2.1\end{array}$

$30^{\prime}$ p Histamine $30 \mathrm{cc} . \quad 0 \quad 6.2$

No symptoms have appeared. The animal is well.

Oct. 9 There is definite atrophy of the papillae of the tongue along the borders and over the tip. The animal is not well and is eating reluctantly.

Oct. 17 R.B.C. 5.04 Hgb. $61 \%$ MCV 44.0 CI .610

Oct. 23 The animal still appears to be in good condition.

R.B.C. 5.38 Hgb. $62 \%$ MCV 48.5 CI .585

Gastric analysis: Vol. $\mathrm{Frel}$ Total $\begin{array}{llll}\text { Fasting } & 5 \mathrm{cc} . & 0 & 6.0\end{array}$ $30^{\prime}$ p Histamine $14 \mathrm{cc} . \quad 0 \quad 12.2$

Oct. 28 Weakness of the hind legs and a moderate anemia have appeared. Diarrhea is severe. The oral administration of liver extract, number 343,4 grams daily, is begun.

R.B.C. 4.74 Hgb. $52 \%$ MCV 50.0 CI .555

Nov. 8 Liver extract treatment is discontinued. The animal is stronger, the weakness of the limbs is no longer present, and an improvement of blood values has occurred.

Nov. 15 R.B.C. 5.22 Hgb. 58\% MCV 56.0 CI .565

Nov. 21 R.B.C. 7.11 Hgb. 70\% MCV 44.0 CI .490

Dec. 4 After one month of freedom from symptoms 
the animal appears weak and ill. The diet is refused.

Dec. 5 Found dead. Autopsy: All the organs appeared normal except for the stomach. The mucosa of the proximal third and of all but the superior surface of the stomach presents a striking alteration. It measures from 2 to $6 \mathrm{~mm}$. in thickness, is a deep brown in color, and is soft and necrotic. There is considerable injection of the submucosa and muscularis. Histological examination shows the mucosa to be necrotic and thickly infiltrated with inflammatory cells and hemorrhagic exudate.
CONTROLS

The presence of the vitamin $B$ complex in the experimental diet

Reference to the literature concerning the diet described by Goldberger as productive of blacktongue in dogs reveals that its content of vitamin $\mathrm{B}$ is not clearly understood. In Goldberger's original publications it was assumed that the diet was deficient in a part of the vitamin B complex. This assumption was based upon the fact that the symptoms resulting from the feeding of the diet

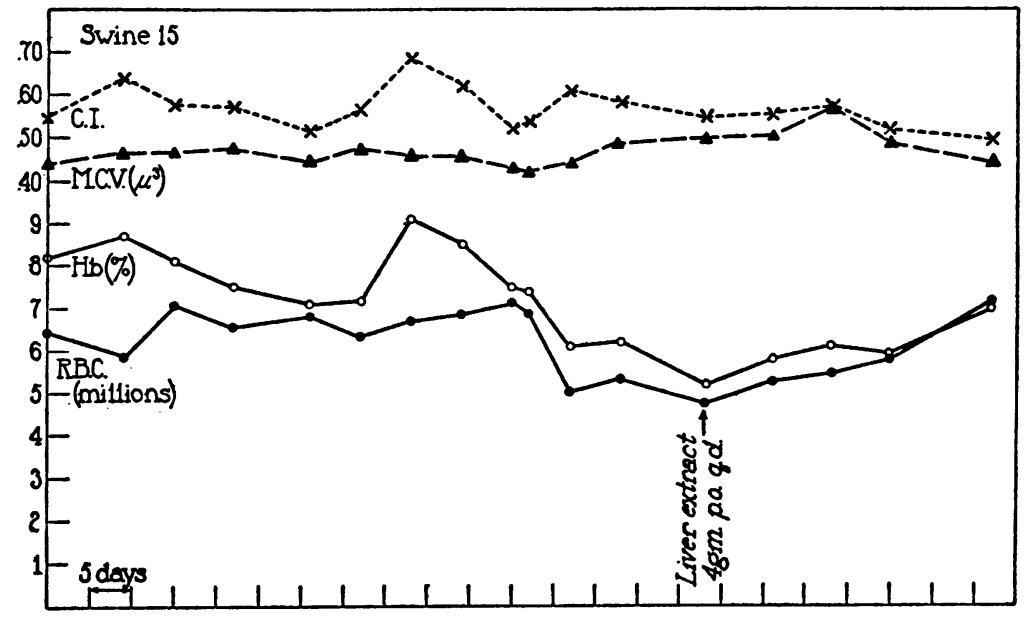

Fig. 4. A Graph of the Changes in Blood Levels of Swine 15.

In this experiment (Figure 4) the animal presented achlorhydria, anemia which was not macrocytic in character and weakness of the extremities. Atrophy of the papillae of the tongue was intermittently present. The anemia was moderately severe, but the color index and mean corpuscular volume were not altered. There was an imiprovement of blood values on oral therapy with liver extract.

The protocols are typical of the entire group. The only striking difference between these animals and those previously discussed lies in the fact that the anemia was not markedly macrocytic in type. Iron was given throughout the course of the experiment and did not prevent the anemia. The similarity of the two groups, both in the response to therapy as well as in the pathological alterations of the bone marrow, suggest the conclusion that the two types of anemia are manifestations of a different individual susceptibility. did not occur if it was supplemented by materials such as yeast, liver, liver extract, meat, milk or a variety of other foodstuffs. The power of preventing black-tongue possessed by those foods was roughly parallel to their known content of watersoluble vitamin B. Hence, the power of preventing black-tongue was supposed to be due to the presence of that vitamin. The dietary constituent which prevented black-tongue was found to be heat-resistant, however, a fact which sharply differentiated it from the thermolabile, anti-neuritic fraction of vitamin $B$. Accordingly, the fraction which was preventive of black-tongue was named vitamin $B_{2}$, or $G$. Since it became known that a thermostable, as well as a thermolabile, fraction was necessary for the growth of rats, it was assumed that the factor promoting rat-growth and the one preventing black-tongue were the same.

Experiments were performed to ascertain if the 
black-tongue-producing diet, supposedly deficient in thermostable, water-soluble, growth-promoting vitamin, was deficient in fact. This point was of particular importance, since it was found impossible to cause black-tongue by feeding diets devoid of vitamin B and otherwise complete. The technique of the experiments has been described. necessary to confirm the supposition that a lack of vitamins $\mathrm{A}, \mathrm{C}$ and $\mathrm{D}$ bore no relation to the production of the disease syndrome. The method employed was to feed swine on a basal diet which was known to be deficient in vitamins $A, C$ and $D$, as well as in $B_{1}$ and $B_{2}(G)$. To this diet were added substances known to contain the dietary

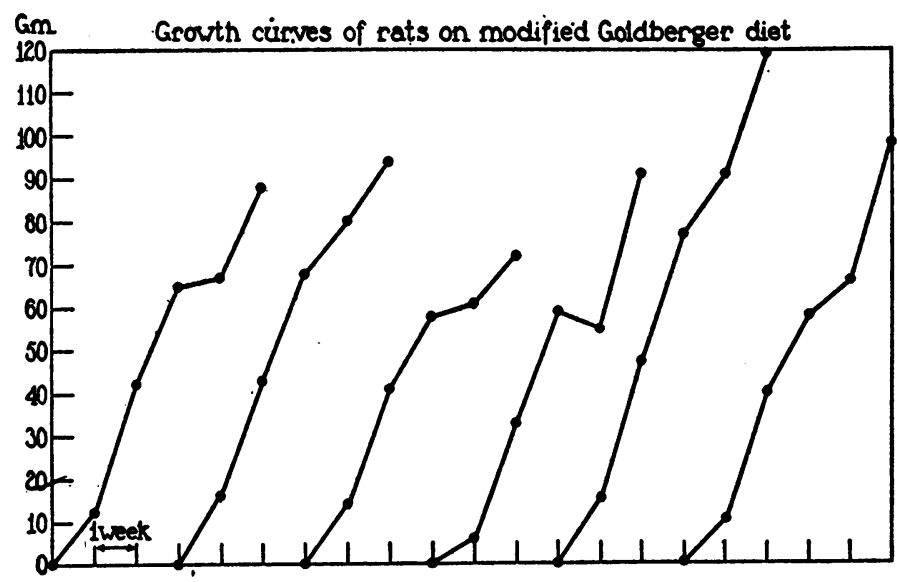

Fig. 5. Graph Showing the Weekly Gain in Weight of Rats Fed the Modified Goldberger Diet.

In Figure 5 are presented the growth curves of six rats which were fed this modified Goldberger diet over a period of five weeks. All showed a consistent normal weekly growth gain over the entire period, and several gained as much as from 30 to $\mathbf{4 0}$ grams per week. The average weekly gain of each animal was 18.7 grams. Therefore, it is evident that the experimental diet which was fed to the swine reported in this communication contained an amount of vitamins $B_{1}$ and $B_{2}(G)$ adequate to support normal growth in rats. Moreover, similar experiments were performed by feeding the original Goldberger number 123 black-tongue-producing diet without the addition of rice polishings, and exactly the same results were obtained. That diet also contained sufficient vitamin B to allow a normal rate of growth in young rats.

Control for the effect of a deficiency of vitamins other than vitamins $B_{1}$ and $B_{2}(G)$

Although cod-liver oil was added to the modified Goldberger diet, and although orange juice was given to the pigs receiving this diet, it seemed anti-anemia constituent. To the diet of two of the animals, 4 grams of Vegex were added, while to the diet of the others 20 grams of egg white were added. Other swine were fed the basal diet without the addition of any material rich in vitamin content.

The animals were kept under the same uniform conditions and studies were made by the same methods and in the same detail as were the studies of the animals fed the modified Goldberger diet. A summary of the hematological studies is presented in Table IV.

Mouth lesions, gastro-intestinal disturbances and paralysis were never observed in any of these animals. All of them became achlorhydric much sooner than did the animals fed the modified Goldberger diet (Table I). This achlorhydria could not be relieved by treating the animals with large amounts of vitamin $B_{1}$. Although the average duration of life was longer for these animals than for any of the others (Table I), no considerable hematological change appeared at any time. On the other hand, similar controls fed the basal vitamin-free diet until death without the addition of substances containing the anti-anemic constituent, 
HEMATOPOIETIC ELEMENTS OF GASTRIC SECRETION AND LIVER

TABLE IV

The average maximum variation in blood levels of control swine

\begin{tabular}{|c|c|c|c|c|c|c|c|c|}
\hline \multirow{2}{*}{$\begin{array}{l}\text { Swine } \\
\text { number }\end{array}$} & \multicolumn{4}{|c|}{ Initial blood levels } & \multicolumn{4}{|c|}{ Maximum change of blood levels } \\
\hline & R.B.C. & $\mathrm{Hgb}$. & $\mathrm{MCV}$ & $\mathrm{CI}$ & R.B.C. & $\mathrm{Hgb.}$ & $\mathrm{MCV}$ & CI \\
\hline Average & 7.97 & 86.5 & 49.0 & .513 & 6.96 & 72.5 & 45.3 & .523 \\
\hline
\end{tabular}

also failed to show considerable hematological effects.

To summarize: the modified Goldberger diet contained amounts of vitamin $B_{1}$ and $B_{2}(G)$ adequate to support a normal rate of growth in rats under standard conditions. Since swine which were fed a diet deficient in vitamins A, C and $\mathrm{D}$, but to which the extrinsic anti-anemia factor was added, did not develop either anemia or other characteristic disease manifestations, it would appear that a lack of vitamins A, C and D bore no relation to the production of the pathological changes under discussion. Furthermore, since the diet which produced the syndrome in animals was shown to contain vitamins $B_{1}$ and $B_{2}(G)$, and the syndrome could not be produced by feeding diets lacking those vitamins, it would also appear that a deficiency of any known fraction of vitamin $B$ was not etiologic.

\section{BONE MARROW STCDIES}

Bone marrow of normal sivine. The femoral marrows of eight normal swine were studied. Grossly, they were very fatty and a bright yellow in color. By microscopic examination (Figure 6) they were extremely hypoplastic with almost the entire marrow space occupied by fat cells. The venous sinusoids were open and occasionally adult red blood cells were seen. In some of the intercellular spaces normoblasts and white blood cells were present.

Bone marrow of saine arith anemia. There was no appreciable difference detectable in the bone marrows of the two groups of animals. Figure 7 shows a photograph of a biopsy taken from the femur of one of the animals soon after the experimental feeding was begun. This mar- row is extremely acellular and corresponds in every respect with that of normal animals. In contrast to this is the marrow taken from the same animal at autopsy ten weeks later, when achlorhydria and a severe macrocytic anemia had developed (Figures 8 and 9). The marrow, grossly, was a deep reddish purple in color. Its consistency was firm and elastic. Microscopically, hyperplastic tissue has replaced the fat cells. The blood sinuses are collapsed and adult erythrocytes are rare. The predominating cell is large

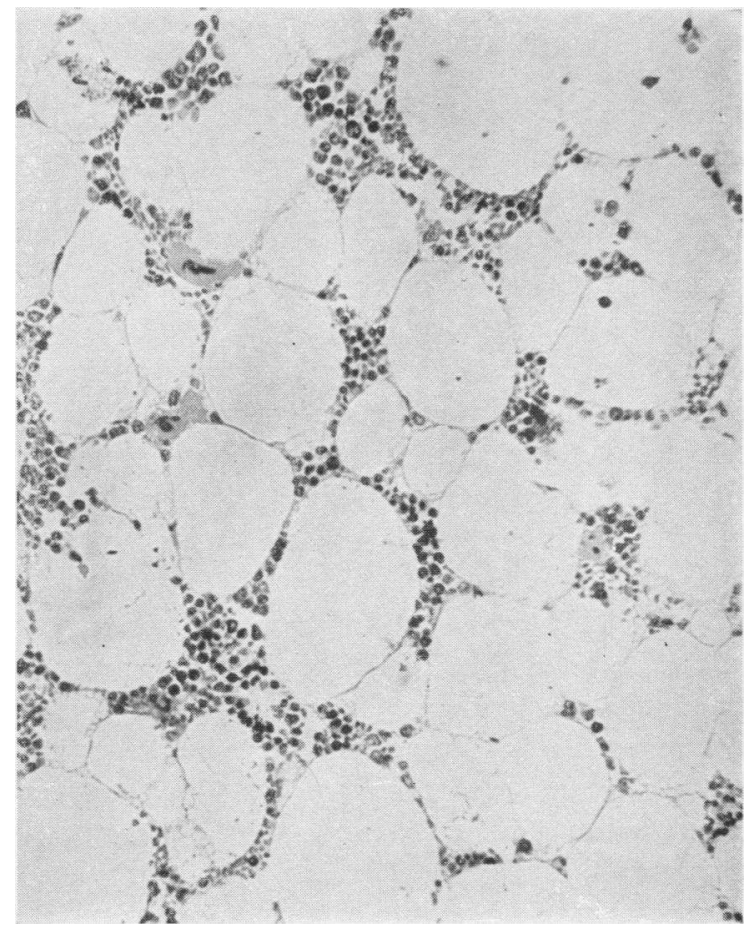

Fig. 6. Photomicrograph of the Femoral Bone Marrow of a Normal Swine

$\times$ 300. Giemsa stain. 


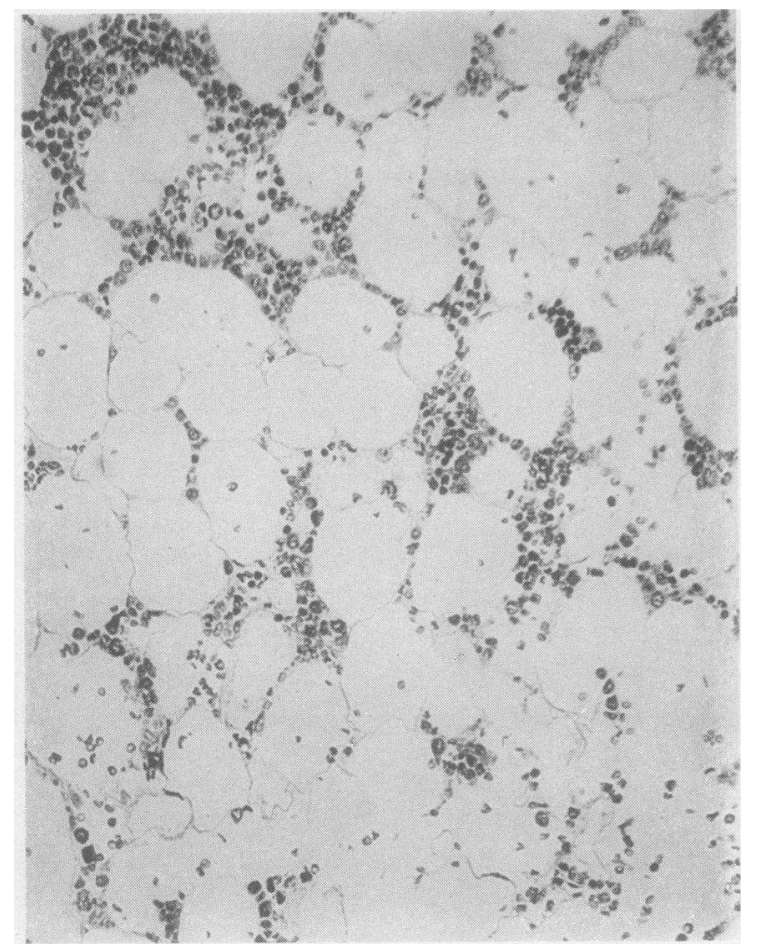

Fig. 7. Photomicrograph of the Femoral Bone Marrow of One of the Experimental Swine Removed by Biopsy before the Diet Feeding Was Begun. $\times 300$. Giemsa stain.

with a pale, vesicular nucleus, the chromatin of which is arranged loosely about the periphery. The cytoplasm of the cell is basophilic in character and irregular in outline. Mitotic figures are frequent. Classified according to the terminology of Sabin, the cells just described are termed megaloblasts. Erythroblasts, small ovoid cells with heavy nuclear chromatin and hemoglobin in the cytoplasm, both of the early and late types, are more commonly seen than are normoblasts. There is some white-cell hyperplasia, with myelocytes predominating.

Very advanced bone-marrow alterations occurred in only three instances. However, in the remaining marrows varying degrees of cellular hyperplasia of the same general type were present. In many, collections of megaloblasts were found, although the fat spaces had not entirely disappeared. In such marrows late erythroblasts predominate and adult erythrocytes were numerous. In no instance was a marrow of the normoblastic type seen in the microcytic anemias observed. In occasional instances, however, the

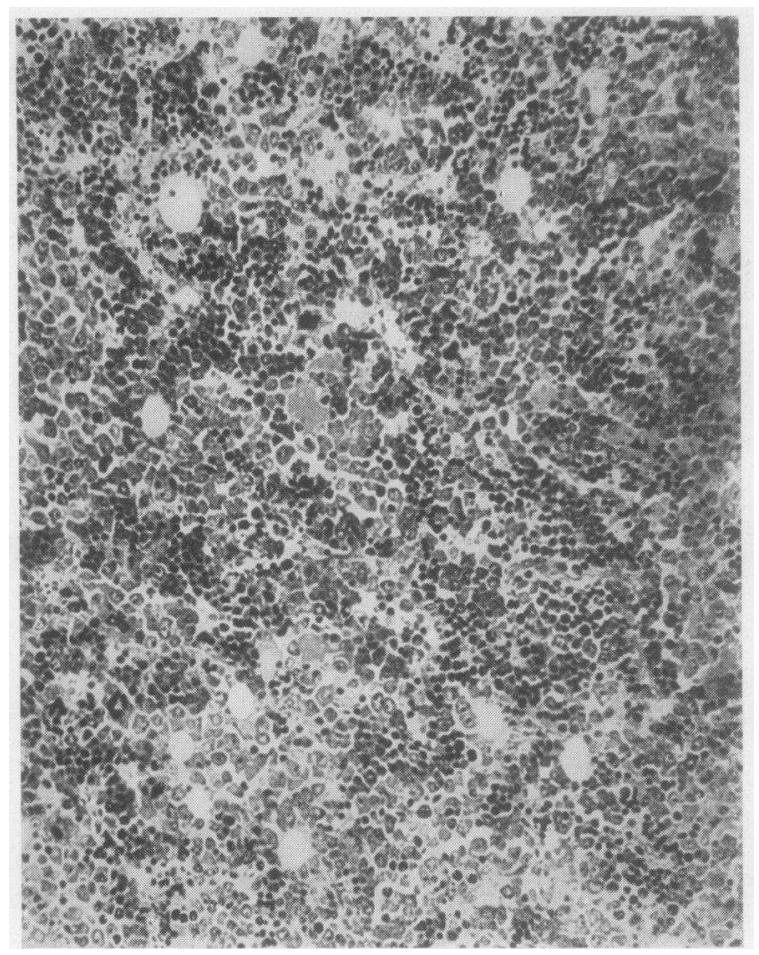

Fig. 8. Low-power Photomicrograph of the Femorai. Bone Marrow of the Same Animal as in Figure 7, after Severe Macrocytic Anemia Had Developed. $\times$ 300. Giemsa stain.

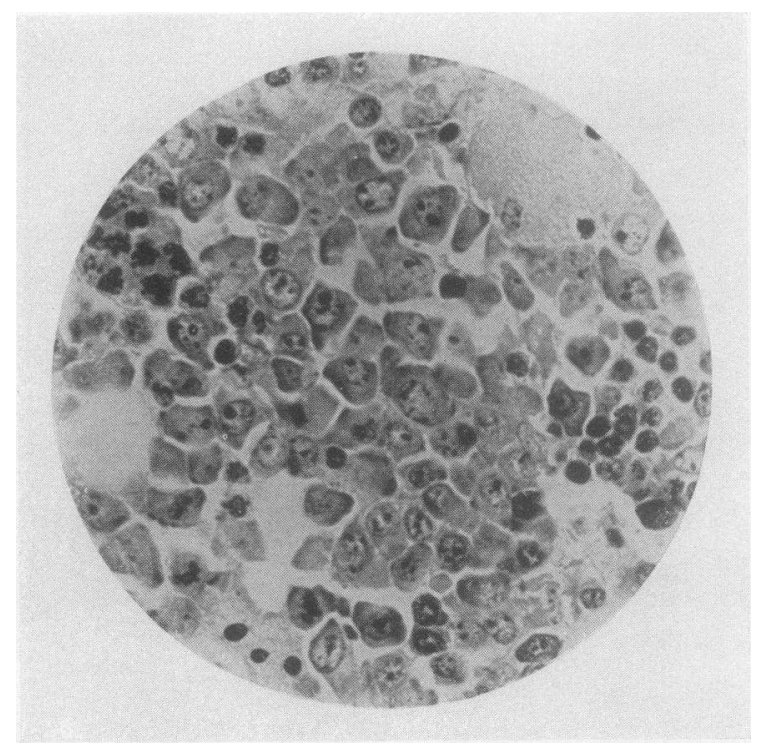

Fig. 9. High-power Photomicrograph of the Same Femoral Marrow as Shown in figure 8. $\times 1000$. Giemsa stain. 
myelocytic hyperplasia was equal to or greater than that of the erythrocytic type. Two of the marrows were not more active than normal. The changes described are in general comparable to those found in the marrow in cases of tropical sprue with anemia, by Rhoads and Castle (20).

The presence of hematopoietic factor in the gastric juice of swine with experimental achlorhydria and anemia

The method chosen to determine the presence or absence of the anti-anemic factor in the gastric juice of swine presenting the symptom-complex under discussion was that used by Castle (21) to demonstrate the presence of the same factor in human beings. A digest prepared by incubating 12 grams of Vegex with $150 \mathrm{cc}$. of gastric juice, obtained from individual swine with achlorhydria and anemia, was fed daily to a patient with pernicious anemia at a low hematological level. After ten days of such treatment gastric juice from normal swine was substituted for the secretion days a digest with gastric juice from anemic swine was fed, no increase of reticulocytes occurred, and the blood values fell to 1,410,000 erythrocytes and a hemoglobin of 33 per cent. On the tenth day the second period was begun, in which the effect of the substitution of gastric secretion from normal swine for that of the pathological animal was tested. At the beginning of this period the red blood cell count was $1,460,000$, the hemoglobin 34 per cent, and the reticulocyte count 0.2 per cent. On the fifth day thereafter, the reticulocyte count rose to 2.0 per cent, on the sixth day to 8.4 per cent, and on the eighth day to 28.2 per cent. This was followed by a rise of the red blood cell count to $1,730,000$ and the hemoglobin to 38 per cent on the tenth day, and to $2,060,000$ with a hemoglobin of 44 per cent on the fourteenth day. From this experiment it appears that the gastric juice of the swine in which anemia and achlorhydria had developed did not contain the anti-anemia ferment which is present in the gastric juice of normal swine.

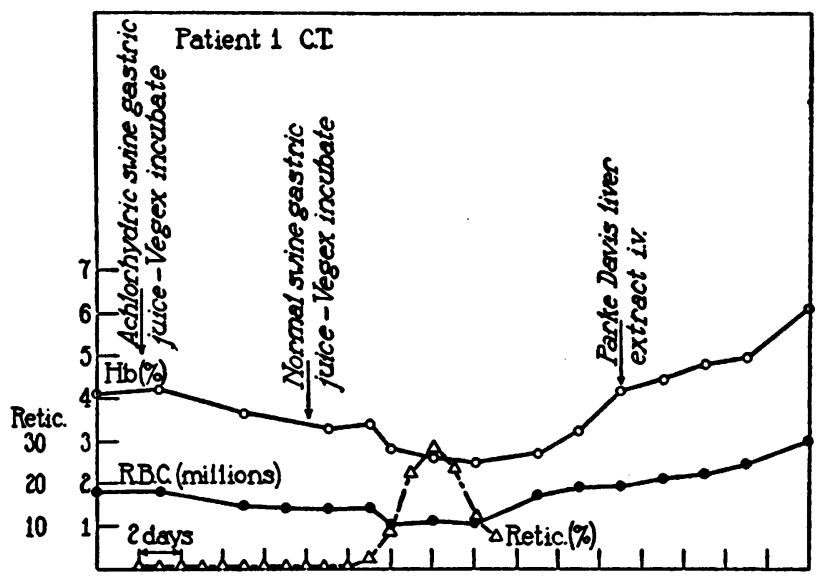

Fig. 10. A Graph of the Changes in Blood Levels of a Patient with Pernicions Anemia During the Feeding of Digests of Vegex with Normal and with Experimental Swine Gastric Juice.

of the pathological animal. The reticulocytes were counted daily.

In Figure 10 and Table V, are presented the blood changes observed in Patient 1 during these two courses of therapy. At the beginning of the experiment the red blood cell count was $1,750,000$, the hemoglobin 42 per cent, and the reticulocyte count 0.8 per cent. During the following nine
Tests for the presence of the anti-anemia factor in the livers of swine with anemia and achlorhydria

In order to determine the presence of the antianemia factor in animals which developed the symptom-complex described, their livers were extracted and the resultant material administered parenterally to patients with pernicious anemia. 
TABLE V

The changes in blood levels of Patient 1,C.T., with pernicious anemia during the feeding of digests of Vegex with normal and with experimental swine gastric juice

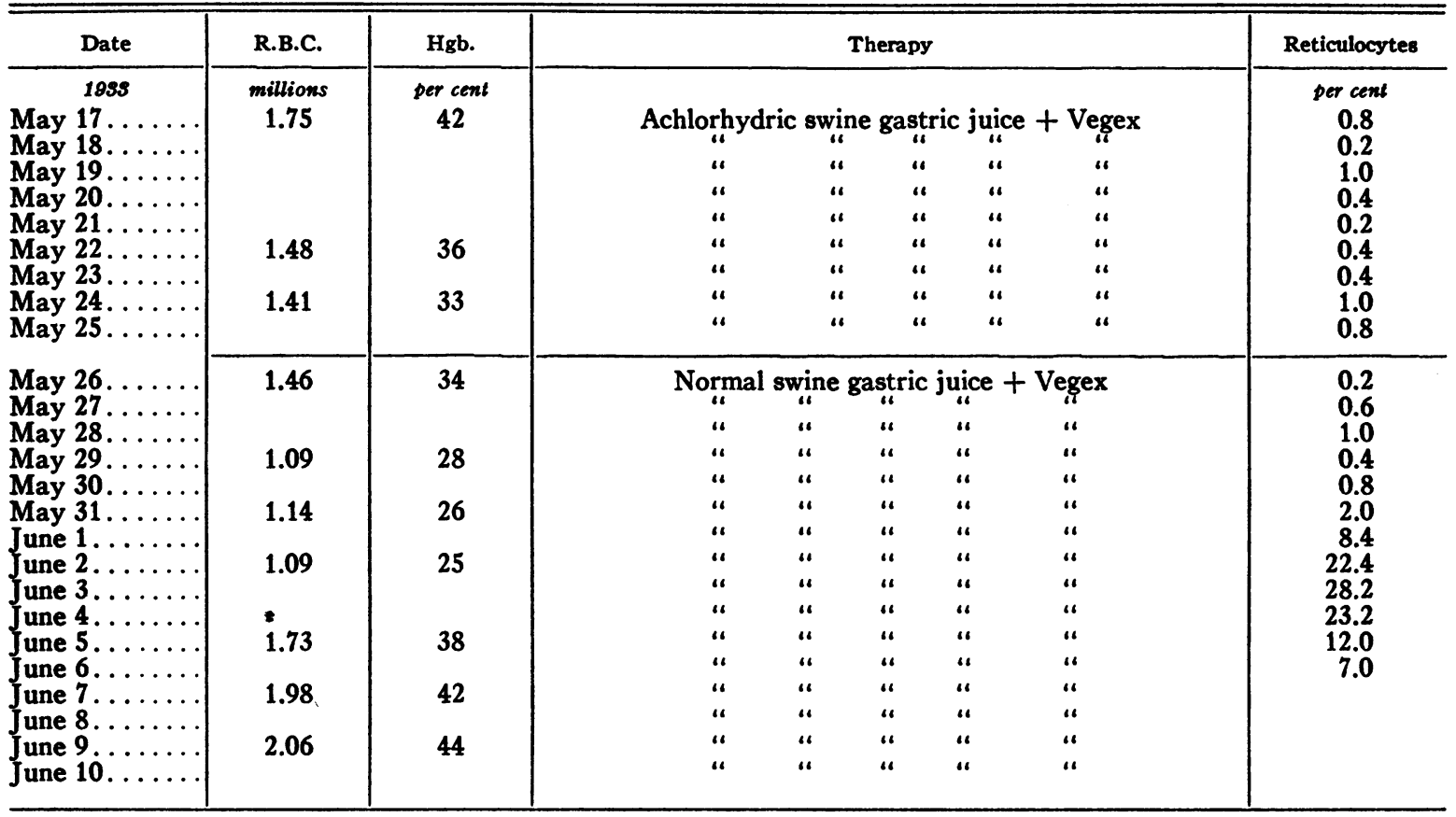

The extracts were given intravenously over a period of ten days, during which red blood cell and reticulocyte levels were followed closely. Following this period of therapy, liver extract made by the same method from the livers of normal pigs was substituted and the blood studies continued.

In Figure 11 and Table VI, are presented the

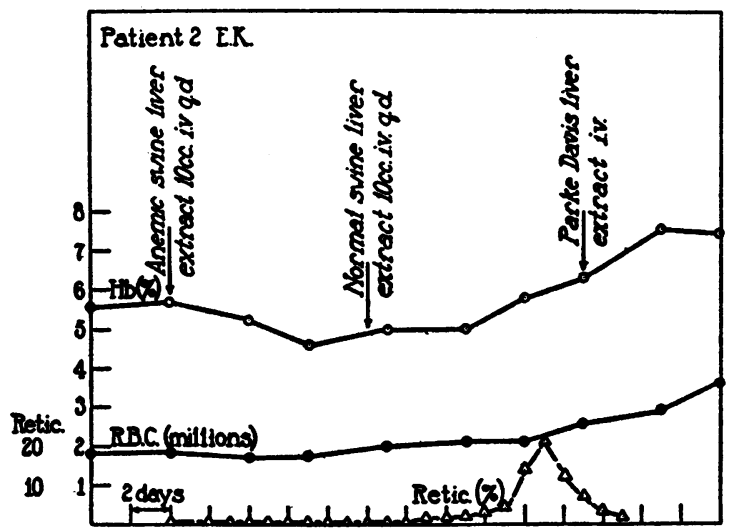

Fig. 11. A Graph of the Changes in Blood Levels of a Patient with Pernicious Anemia During the Administration of Extracts of Anemic aNd Normal SWINE LIVERS.
TABLE VI

The changes in blood levels of Patient 2, E. K., with pernicious anemia during the injection of extracts of the livers of anemic and of normal swine.

\begin{tabular}{|c|c|c|c|c|c|}
\hline \multirow{2}{*}{ Date } & \multirow{2}{*}{ R.B.C. } & \multirow{2}{*}{ Hgb. } & \multicolumn{2}{|c|}{ Therapy (intravenous) } & \multirow{2}{*}{$\begin{array}{l}\text { Reticu- } \\
\text { locytes }\end{array}$} \\
\hline & & & Liver extract & Dose & \\
\hline $\begin{array}{c}1933 \\
\text { September } 8 \ldots \\
\text { September } 9 \ldots \\
\text { September } 10 . \\
\text { September } 11 . \\
\text { September } 12 \ldots \\
\text { September } 13 . \\
\text { September } 14 . \\
\text { September } 15 . \\
\text { September } 16 . . \\
\text { September } 17 . .\end{array}$ & $\begin{array}{c}\text { millions } \\
1.89 \\
\\
1.78 \\
1.80\end{array}$ & $\begin{array}{c}\text { per cent } \\
57 \\
52 \\
46\end{array}$ & 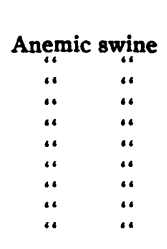 & $\begin{array}{l}c c . \\
10 \\
10 \\
10 \\
10 \\
10 \\
10 \\
10 \\
10 \\
10 \\
10\end{array}$ & $\begin{array}{c}\text { per cent } \\
0.6 \\
0.6 \\
0.4 \\
0.2 \\
0.2 \\
0.6 \\
0.2 \\
0.4 \\
0.4 \\
0.6\end{array}$ \\
\hline $\begin{array}{l}\text { September } 18 . \\
\text { September } 19 . \\
\text { September } 20 . \\
\text { September } 21 . \\
\text { September } 22 . \\
\text { September } 23 . \\
\text { September } 24 . \\
\text { September } 25 . \\
\text { September } 26 . \\
\text { September } 27 . \\
\text { September } 28 . \\
\text { September } 29 . \\
\text { September } 30 . \\
\text { October } 1 \ldots \ldots \\
\text { October } 2 \ldots \ldots \\
\text { October } 3 \ldots \ldots \\
\text { October } 4 \ldots \ldots \\
\text { October } 5 \ldots \ldots \\
\text { October } 6 \ldots \ldots\end{array}$ & $\begin{array}{l}2.18 \\
2.12 \\
2.57\end{array}$ & $\begin{array}{l}50 \\
58 \\
63\end{array}$ & 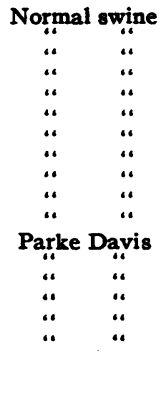 & $\begin{array}{l}10 \\
10 \\
10 \\
10 \\
10 \\
10 \\
10 \\
10\end{array}$ & $\begin{array}{r}0.4 \\
0.8 \\
2.0 \\
2.0 \\
2.2 \\
3.0 \\
3.0 \\
4.2 \\
14.2 \\
21.2 \\
12.8 \\
7.6 \\
3.2 \\
2.0\end{array}$ \\
\hline
\end{tabular}


results of one such experiment (Patient 2). The patient, over a ten-day period, received intravenously an amount of extract derived from 500 grams of whole liver. At the beginning of the study the erythrocyte count was $1,890,000$, the hemoglobin 57 per cent, and the reticulocyte count 0.6 per cent. During this entire first ten-day period the red blood cell count did not change essentially, nor was an increase of reticulocytes observed. On the eleventh day the patient was given, by the same route, a similar amount of liver extract made by the same procedure, but from the livers of normal swine. At this time the red blood cell count was 2,060,000, and the hemoglobin 50 per cent. On the sixth day the reticulocyte count rose to 3 per cent, on the seventh day to 4.2 per cent, on the eighth day to 14.2 per cent, and on the ninth day to 21.2 per cent. Following this, the red blood cell count rose on the eleventh day to 2,570,000, and the hemoglobin to 63 per cent. The patient received in all an amount of liver extract derived from 400 grams of normal swine liver.

In Figure 12 and Table VII, are presented the blood studies of Patient 3. The experiment was similar to the one just described except that the injections were given for thirteen days and an amount of liver extract derived from 650 grams of liver was administered. At the beginning of this first period the red blood cell count was $2,200,000$, the hemoglobin 63 per cent, and the reticulocyte count 0.8 per cent. During the en-

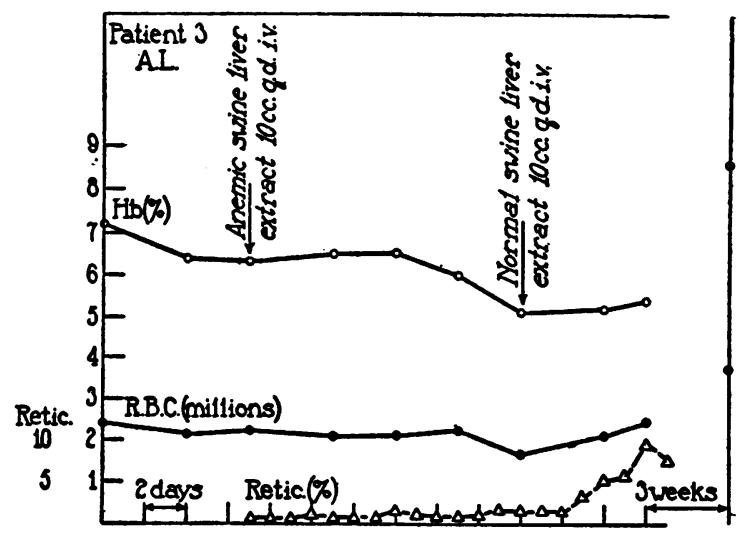

Fig. 12. Graph of the Changes in Blood Levels of Patient 3 with Pernicious Anemia During the INJECTION OF Extracts OF THE LIVERS OF ANEMIC AND Normal Swine.
TABLE VII

The changes in blood levels of Patient 3, A. L., with pernicious anemia during the injection of extracts of the livers of anemic and normal swine.

\begin{tabular}{|c|c|c|c|c|c|}
\hline \multirow{2}{*}{ Date } & \multirow{2}{*}{ R.B.C. } & \multirow{2}{*}{ Hgb. } & \multicolumn{2}{|c|}{ Therapy (intravenous) } & \multirow{2}{*}{$\begin{array}{l}\text { Reticu- } \\
\text { locytes }\end{array}$} \\
\hline & & & Liver extract & Dose & \\
\hline $\begin{array}{c}1939 \\
\text { September } 16 . . \\
\text { September } 17 . \\
\text { September 18. } \\
\text { September 19.. } \\
\text { September 20.. } \\
\text { September } 21 . \\
\text { September 22. } \\
\text { September 23.. } \\
\text { September 24.. } \\
\text { September 25.. } \\
\text { September } 26 . . \\
\text { September 27. } \\
\text { September 28.. }\end{array}$ & 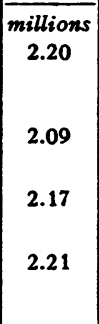 & 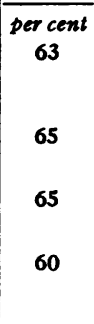 & 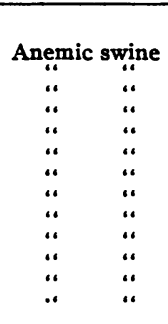 & $\begin{array}{l}c c . \\
10 \\
10 \\
10 \\
10 \\
10 \\
10 \\
10 \\
10 \\
10 \\
10 \\
10 \\
10 \\
10\end{array}$ & $\begin{array}{c}\text { per cent } \\
0.8 \\
0.6 \\
0.6 \\
1.0 \\
0.6 \\
0.8 \\
0.8 \\
1.2 \\
1.0 \\
0.6 \\
0.8 \\
1.2 \\
1.8\end{array}$ \\
\hline $\begin{array}{l}\text { September } 29 . . \\
\text { September } 30 . . \\
\text { October } 1 \ldots \ldots \\
\text { October } 2 \ldots \ldots \\
\text { October } 3 \ldots \ldots \\
\text { October } 4 \ldots \ldots \\
\text { October } 5 \ldots \ldots\end{array}$ & $\begin{array}{l}1.68 \\
2.18 \\
2.48\end{array}$ & $\begin{array}{l}62 \\
64\end{array}$ & 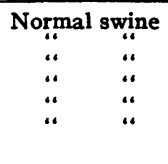 & $\begin{array}{l}10 \\
10 \\
10 \\
10 \\
10 \\
10\end{array}$ & $\begin{array}{l}1.6 \\
1.4 \\
2.8 \\
5.2 \\
5.8 \\
9.2 \\
7.4\end{array}$ \\
\hline
\end{tabular}

tire period of thirteen days there was no improvement in the blood values and no rise in the reticulocyte count. On the second day after the injection of normal pig liver extract, the reticulocytes rose to 2.8 per cent, on the fourth day to 5.8 per cent, and on the fifth day to 9.2 per cent. This was followed by an improvement of the blood values, the red count rising to $2,480,000$ and hemoglobin to 64 per cent. An amount of liver extract derived from 300 grams of normal swine liver was given.

From the experiments described, it appears that the livers of the swine which developed the syndrome of achlorhydria, anemia and mouth lesions did not contain the anti-anemia substance which is present in the livers of normal swine.

\section{DISCUSSION}

From the experimental evidence presented, it appears that by feeding to swine a diet which causes canine black-tongue, a characteristic symptom-complex can be produced. Macrocytic anemia, lesions of the oral mucous membrane, gastric achlorhydria, diarrhea and motor weakness of the extremities were the principal manifestations. When the disease was present it was impossible to demonstrate hematopoietic activity of the gastric secretion or liver when tested on cases of pernicious anemia in man. The gastric secretions 
and livers of normal swine did possess hematopoietic power when tested in exactly the same manner.

The disease syndrome of swine could be prevented and alleviated by the administration of certain substances which are prophylactic and curative of sprue, tropical macrocytic anemia, pellagra and pernicious anemia in man. The symptomatic, pathologic, physiologic and therapeutic similarity between the experimental disease of swine and a group of pathologic states of human beings was striking; so much so, that the inference is unavoidable that in man the pathologic changes are due, in part at least, to a common cause, and that the cause is basically a lack of intake or utilization of some as yet poorly defined dietary constituent. Certain objections to this broad conclusion exist, however, and several details require further discussion.

As previously stated, the anemia produced was usually sharply macrocytic in type, presenting morphological changes seen in the stained blood smear which were consistent with those shown by the blood of the macrocytic anemias of man. In several instances, however, microcytosis was the rule, but in such instances the hypochromia was never of the marked degree observed in experimental anemias resulting from a lack of the building stones of the hemoglobin molecule such as iron or copper. It more closely resembled the mild microcytosis frequently observed early in the course of tropical sprue and more rarely late in the course of that disease when a multiple deficiency is present (Castle and Rhoads (1)).

In the experiments, distinct therapeutic responses were obtained by the administration of liver extract, whereas none followed the use of iron alone. That better responses might have been induced had both substances been administered can only be the subject of speculation, since the observations were confined to the use of one or the other material alone. A summation response to the administration of liver extract and iron is occasionally seen in pernicious anemia and frequently in tropical sprue.

The distinct curative effect following the use of liver extract, either orally or parenterally administered, is in keeping with numerous observations on the effect of liver extract in the pre- vention of symptoms when the same diet is fed to dogs (Goldberger and Sebrell (22), Rhoads and Miller (2)).

The changes occurring in the oral mucous membranes deserve special attention. An atrophic glossitis similar to that produced in dogs, and seen in sprue, pellagra and pernicious anemia, was observed in only rare instances. In no animal did it approach in intensity either the canine or the human disease. On the other hand, localized ulcerated lesions of the labial, buccal, lingual, and even laryngeal mucous membrane, were striking in their frequency and extent. For the purpose of discussion, it has been assumed that these lesions are similar in nature to the aphthous stomatitis with ulceration which is so marked a feature of tropical sprue. The histopathology of these changes will be described elsewhere; it suffices to state here that the process is essentially one of coagulation necrosis, apparently similar in nature to, though more localized than, the changes described by Lillie (23) in canine blacktongue. No studies of the aphthous oral lesions of tropical sprue are available for comparison.

As presented in the experimental protocols, one animal showed an acute gastritis at postmortem examination. In other animals there appeared to be a definite loss of thickness with atrophy of the gastric mucous membranes. Histological studies were not wholly satisfactory, since the unavoidable delay intervening between the time of the animal's death and the tissue fixation was suffcient to allow a certain amount of postmortem change to take place. Further investigation of this phase of the problem is proceeding. Clear morphological evidence of alteration of, or damage to, the gastric mucous membrane has certainly not been demonstrated consistently. Evidence of functional damage to the gastric secretory mechanism appeared in almost every experiment, however. Such evidence was at hand in the development of the inability of the stomach to secrete free $\mathrm{HCl}$, and also to secrete a ferment required for hematopoiesis.

Achlorhydria, present even after the injection of histamine, was an early and persistent symptom. It disappeared after treatment in one instance. It is quite impossible, in the present state of knowledge, to speculate concerning the cause 
of this manifestation. It can only be stated that to judge from the studies of the effect of feeding the same diet to other animals the achlorhydria was not due to a lack of any of the known fractions of the vitamin B complex.

The loss of the hematopoietic power of the stomachs of the experimental animal was demonstrated in three experiments, one involving a direct test, and two demonstrating the loss of the presumed stored product of the hematopoietic gastric function in the liver. These experiments require some explanation. Clinical study has shown that in pernicious anemia, and in some cases of sprue, the gastric secretion lacks a ferment which is required to act upon a dietary constituent present in yeast, meat and other substances, to form a substance active in hematopoiesis. In the absence of this gastric activity, the liver is no longer potent in promoting blood formation, Maison and Ivy (7). Hence, test of the hematopoietic function of the liver is indirectly a test of gastric function, and may be more easily performed than the latter. This is due to the fact that potent liver extracts are heat resistant and so may be sterilized and injected into suitable test patients, a procedure not possible with extracts of gastric tissue. In all three of the tests done, a complete lack of hematopoietic function of the diseased animals was shown, a striking contrast to the results of tests of like material prepared from normal animals. The uniform nature of the results suggests definitely that, under the conditions observed, achlorhydria and loss of the anti-pernicious anemia activity of the stomach may follow a deficiency of a specific dietary constituent. That constituent is one which is contained in those substances which are therapeutically active in symptomatically similar conditions of man. Lastly, clinical observation offers incomplete but undeniable evidence that in man similar manifestations may follow deficient intake or absorption of the same substances.

From the reported studies of the modified blacktongue-producing diet, the cause of its pathogenicity is not clear. Since the power of promoting the growth of young rats kept under standard conditions is the only available means of determining the presence or absence of the various fractions of the vitamin B complex, we are forced to conclude that the diet is adequate in its content of that vitamin. The objection may be advanced that the rat and the dog may differ radically in their requirement for vitamin $B$, and hence a diet which is wholly adequate for one animal might be a deficient diet for another. This objection would be valid were it not for the fact that neither in other laboratories nor in the control experiments reported here has black-tongue resulted from feeding diets complete except for the vitamin B complex. Zimmerman and Burack (14) and Bliss (24) have suggested that the diet lacks certain mineral constituents. Opposed to this view is the fact that no experimentally produced mineral deficiency has been reported as causing the symptoms of black-tongue. Furthermore, the symptoms may be prevented by supplementing the diet with a compound such as liver extract, which is exceedingly low in mineral constituents.

The assumption has been widespread that because the symptoms resulting from the feeding of a particular diet are prevented or cured by administering a material which is rich in a particular vitamin, it may be inferred that the symptoms are due to a lack of that vitamin. Since our knowledge of the mode of action of vitamins is seriously deficient, and since in the experiments under discussion an even relatively pure source of vitamin was not available, any conclusion as to the etiological rôle played by a particular vitamin deficiency must be open to question. In the studies reported here, the substances fed as sources of vitamin $B_{2}(G)$ contain an infinite variety of different compounds, among which that vitamin may be one of the least important. No claim for the etiologic or therapeutic activity of vitamin $B_{2}(G)$ is here advanced, and, moreover, it is held that no conclusive proof exists for the therapeutic activity of vitamin $B_{2}(G)$ in sprue, pellagra, pernicious anemia, tropical macrocytic anemia, or canine black-tongue. On the other hand, proof to the contrary is also lacking, so that the matter must be considered quite unsettled at present. The lack of complete understanding of the mode of production of the symptom-complex should not obscure the fact that the feeding of the blacktongue-producing diet gives rise to symptoms in animals which not only simulate pellagra in man, but also when studied under particular experi- 
mental conditions simulate sprue and pernicious anemia.

\section{SUMMARY AND CONCLUSIONS}

1. By feeding a modified canine-black-tongueproducing diet to swine, a symptom-complex marked by oral mucous membrane lesions, achlorhydria and anemia may be caused.

2. The disease is associated with a loss of the anti-pernicious anemia activity of the gastric secretion and liver.

3. Remissions of the anemia and amelioration of symptoms may be induced by the oral or parentéral administration of liver extract.

\section{BIBLIOGRAPHY}

1. Castle, W. B., and Rhoads, C. P., The etiology and treatment of sprue in Porto Rico. Lancet, 1932, $1,1198$.

2. Rhoads, C. P., and Miller, D. K., The production in dogs of chronic black tongue with anemia. J. Exper. Med., 1933, 58, 585.

3. Miller, D. K., and Rhoads, C. P., J. Exper. Med. (In press.)

4. Goldberger, J., and Wheeler, G. A., The experimental production of pellagra in human subjects by means of diet. Hygienic Lab. Bull., U. S. P. H. S., 1920, No. 120, 7.

5. Richter, O., Ivy, A. C., and Meyer, A. F., A study of the dog's stomach and liver for substances effective in pernicious anemia. Proc. Soc. Exper. Biol. and Med., 1933-34, 31, 550.

6. Strauss, M. B., and Castle, W. B., Amount of material effective in pernicious anemia present in dog liver. Proc. Soc. Exper. Biol. and Med., 1933-34, $31,360$.

7. Maison, G. L., and Ivy, A. C., Gastrectomy and subsequent hematologic studies in the hog. Proc. Soc. Exper. Biol. and Med., 1933-34, 31, 554.

8. Seyderhelm, R., Lehmann, W., and Wichels, P., Intestinale, perniziöse Anämie beim Hund durch experimentelle Dünndarmstriktur. Krankheitforschung, 1927, 4, 263.

9. Brown, M. R., The pathology of the gastro-intestinal tract in pernicious anemia and subacute combined degeneration of the spinal cord. New England J. Med., 1934, 210, 473.

10. Davidson, L. S. P., and Leitch, I., The nutritional anaemias of man and animals. Nutrition Abstr. and Rev., 1933-34, 3, 901.

11. Whipple, G. H., and Robscheit-Robbins, F. S., Blood regeneration in severe anemia.

V. Influence of striated and smooth muscle feeding. Am. J. Physiol., 1926-27, 79, 260.
VI. Influence of kidney, chicken and fish livers and whole fish. Ibid., 1926-27, 79, 271.

VII. Influence of dairy products on hemoglobin production. Ibid., 1926-27, 79, 280.

VIII. Influence of bone marrow, spleen, brains and pancreas feeding; the question of organic iron in the diet. Ibid., 1927, 80, 391.

IX. Influence of fresh and dried fruits. Ibid., 1927, 80,400 .

XII. Iron effect separated from organ effect in diet. Ibid., 1927-28, 83, 76.

12. McGowan, J. P., and Sinclair, R. D., A further method of estimating the potency of liver extract. Edinburgh M. J., 1931, 38, 405.

13. Cowgill, G. R., and Gilman, A., Physiology of vitamins. XXIII. The effect of lack of the vitamin B complex on the secretion of gastric juice in dogs with gastric pouches. Arch. Int. Med., 1934, 53, 58.

14. Zimmerman, H. M., and Burack, E., Studies on the nervous system in deficiency diseases. II. Lesions produced in the dog by diets lacking the watersoluble, heat-stable vitamin $B_{2}(G)$. J. Exper. Med., 1934, 59, 21.

15. Peters, J. P., and Van Slyke, D. D., Quantitative Clinical Chemistry. II. Methods. Williams and Wilkins Co., Baltimore, 1931, p. 337.

16. Wintrobe, M. M., The size and hemoglobin content of the erythrocyte. Methods of determination and clinical application. J. Lab. and Clin. Med., 1931-32, 17, 899.

17. Wolbach, S. B., in Mallory, F. B., and Wright, J. H., Pathological Technique. W. B. Saunders Co., Philadelphia, 1924, 8th ed., p. 437.

18. Cohn, E. J., McMeekin, T. L., and Minot, G. R., The nature of the material effective in pernicious anemia. IV. J. Biol. Chem., 1930, 87, p. xlix.

19. Levene, P. A., Concentration of vitamins $B_{1}$ and $B_{2}$. J. Biol. Chem., 1932, 95, 317.

20. Rhoads, C. P., and Castle, W. B., The pathology of the bone marrow in sprue anemia. Am. J. Path., 1933, 9, 813.

21. Castle, W. B., Observations on the etiologic relationship of achylia gastrica to pernicious anemia. I. The effect of the administration to patients with pernicious anemia of the contents of the normal human stomach recovered after the ingestion of beef muscle. Am. J. M. Sc., 1929, 178, 748.

22. Goldberger, J., and Sebrell, W. H., The black-tongue preventive value of Minot's liver extract. Pub. Health Rep., U. S. P. H. S., 1930, 45, 3064.

23. Lillie, R. D., Pathology of experimental black-tongue. Nat. Institute Health Bull., 1933, No. 162, 13.

24. Bliss, S., Considerations leading to the view that pellagra is an iron-deficiency disease. Science, 1930, 72, 577. 